\title{
Metal Zirconium Phosphate Macroporous Monoliths: Versatile Synthesis, Thermal Expansion and Mechanical Properties
}

Yang Zhu ${ }^{\mathrm{a}}$, Kazuyoshi Kanamori ${ }^{\mathrm{a}}$, Nirmalya Moitra ${ }^{\mathrm{a}}$, Kohei Kadono ${ }^{\mathrm{b}}$, Shugo Ohi ${ }^{\mathrm{c}}$, Norimasa

$$
\text { Shimobayashi }^{\mathrm{d}}, \text { Kazuki Nakanishi }^{* a}
$$

${ }^{a}$ Department of Chemistry, Graduate School of Science, Kyoto University, Kitashirakawa, Sakyo-ku,

$$
\text { Kyoto 606-8502, Japan }
$$

${ }^{\mathrm{b}}$ Graduate School of Chemistry and Materials Technology, Kyoto Institute of Technology, Matsugasaki, Sakyo-ku, Kyoto 606-8585, Japan

${ }^{c}$ Faculty of Education, Shiga University, Banba, Hikone, Shiga 522-8522, Japan

${ }^{\mathrm{d}}$ Division of Earth and Planetary Sciences, Graduate School of Science, Kyoto University,

Kitashirakawa, Sakyo-ku, Kyoto 606-8502, Japan

*Corresponding author: Associate Professor Dr. Kazuki Nakanishi, Department of Chemistry,

Graduate School of Science, Kyoto University, Kitashirakwa, Sakyo-ku, Kyoto 606-8502, Japan

E-mail: kazuki@kuchem.kyoto-u.ac.jp

TEL/FAX: +8175 7532925 


\section{Abstract}

A versatile synthetic method has been developed for the fabrication of metal zirconium phosphate (MZP) macroporous monoliths via a sol-gel process accompanied by phase separation. More than 30 kinds of MZP monolithic polycrystalline monoliths with co-continuous macroporous structure have been synthesized by simply adding the target metal salt in the starting solution with optimized compositions. Glycerol, due to its high boiling point, plays the key role as the solvent to prevent metal salt from recrystallization, allowing a homogeneous distribution of metal salts over the polymerizing zirconium phosphate network. Hierarchically porous polycrystalline strontium zirconium phosphate $(\mathrm{SrZrP})$ monolith has been obtained when the dried gel was calcined at $800{ }^{\circ} \mathrm{C}$. Very low thermal expansion (coefficient of thermal expansion (CTE) as $1.4 \times 10^{-6} \mathrm{~K}^{-1}$ ) over a wide temperature range $\left(38{ }^{\circ} \mathrm{C}\right.$ to $\left.1000{ }^{\circ} \mathrm{C}\right)$ together with good mechanical properties (flexural modulus as 8.0 GPa from 3 point bending test and Young's modulus as $1.9 \mathrm{GPa}$ from uniaxial compression test) has been demonstrated, while high porosity ( $43 \%$ ) due to the presence of macropores reduces bulk density. As compared with dense ceramics of the same composition, the CTE value is lower and can be attributed to the presence of nanometer-sized small pores, which absorbs the anisotropic thermal expansion of each crystallite in the macropore skeletons at elevated temperatures. 
Key words: Sol-gel, Metal zirconium phosphate, Hierarchical porosity, Ultralow thermal expansion,

Mechanical property

\section{Introduction}

Porous materials are commonly found in our daily life as filters [1], heat/sound insulators [2], refractory [3], adsorbents [4] and artificial bone [5], and are gaining increasing importance in energy and environmental applications as electrodes [6], sensors [7], separation media [8], catalysts and catalyst supports [4, 9]. Among them, three-dimensionally continuous (co-continuous) macroporous monoliths (pore diameter $>50 \mathrm{~nm}$ ) are attracting more and more attentions due to the enhanced flow-through property, especially when a pressure driven flow is applied. Not only the mass transfer in the monolith is accelerated, but higher efficiency for the reaction or interaction between the material and reactants than that of conventional fixed-bed reactor is observed with lower pressure drop [10-14]. In the past two decades, the methodology for the synthesis of co-continuous macroporous monoliths via the sol-gel process accompanied by phase separation has been established and successfully applied to different systems, such as inorganic oxides (ceramics) [15], organic polymers [16], and organic-inorganic hybrid systems [17]. However, as compared with other monolithic materials, few successes have been reported in the synthesis of co-continuous metal phosphates monoliths mainly due to their low solubility in aqueous medium. Instead of 
homogeneous sol-gel transition to a monolithic gel, heterogeneous polymerization dominates and leads to precipitation in most cases. In recent years, we have successfully synthesized monolithic ceramics of calcium phosphate [18], lithium iron phosphate [19] and zirconium phosphate (ZrP) [20] with co-continuous macropores. As an important category of inorganic phosphate materials closely related to ZrP, MZP materials are widely used as solid-state electrolytes with high ion conductivity at relatively low temperatures [21], ion exchangers for solidification of nuclear waste [22] as well as ceramics with ultralow thermal expansion over a broad temperature range [23, 24]. Although solid-state synthesis is generally applied to obtain MZP ceramics, it usually requires high sintering temperature and finds difficulty in inducing high porosity (> $40 \%)$ with controlled pore parameters. The sol-gel process is more cost-friendly, because the milder reaction conditions at lower temperatures can be employed in aqueous media. However, metal ions tend to be washed away or recrystallize into the original metal salts after the removal of solvent, causing serious inhomogeneity in the bulky ceramics. Tedious post treatments such as ball milling and high calcination temperature are generally required in order to obtain compositionally homogeneous materials.

Herein based on our previously reported synthetic method for $\mathrm{ZrP}$ [20], we introduce the versatile synthesis of more than 30 kinds of compositionally homogeneous polycrystalline MZP monoliths with co-continuous macroporous structure. Influences of the starting compositions and post heat treatment on the pore structure formation and crystal phase evolution are discussed with $\mathrm{SrZrP}$ as an 
example. Effect of pore structure on the thermal expansion property and the mechanical property of the obtained SrZrP macroporous monoliths are studied.

\section{Experimental}

\subsection{Reagents}

Zirconium oxychloride octahydrate (Wako Pure Chemicals Ind., Ltd., Osaka, Japan) as the zirconium source and concentrated phosphoric acid ( $\geq 85 \mathrm{wt} \%$ in $\mathrm{H}_{2} \mathrm{O}$, Sigma-Aldrich Co. USA) as the phosphate source were used. A mixture of distilled water (Hayashi Pure Chemicals Ind., Co., Ltd., Japan), hydrochloric acid (Kishida Chemical, Japan) and glycerol (Kishida Chemical, Japan) was used as the solvent. Both poly(ethylene oxide) (PEO, average molecular weight 35,000, Sigma-Aldrich Co., USA) and polyacrylamide (PAAm, average molecular weight 10,000, $50 \mathrm{wt} \%$ in $\mathrm{H}_{2} \mathrm{O}$, Sigma-Aldrich Co., USA) were used as the phase-separation inducers. Metal sources were $\mathrm{LiCl}, \mathrm{NaCl}, \mathrm{KCl}, \mathrm{RbCl}, \mathrm{CsCl}, \mathrm{MgCl}_{2} \cdot 6 \mathrm{H}_{2} \mathrm{O}, \mathrm{CaCl}_{2} \cdot 2 \mathrm{H}_{2} \mathrm{O}, \mathrm{SrCl}_{2} \cdot 6 \mathrm{H}_{2} \mathrm{O}, \mathrm{NiCl}_{2} \cdot 6 \mathrm{H}_{2} \mathrm{O}, \mathrm{CuCl}_{2} \cdot 2 \mathrm{H}_{2} \mathrm{O}$, $\mathrm{ZnCl}_{2}, \mathrm{MnCl}_{2} \cdot 4 \mathrm{H}_{2} \mathrm{O}, \mathrm{CoCl}_{2} \cdot 6 \mathrm{H}_{2} \mathrm{O}, \mathrm{AlCl}_{3} \cdot 6 \mathrm{H}_{2} \mathrm{O}, \mathrm{YCl}_{3} \cdot 6 \mathrm{H}_{2} \mathrm{O}, \mathrm{CeCl}_{3} \cdot 7 \mathrm{H}_{2} \mathrm{O}, \mathrm{FeCl}_{3} \cdot 6 \mathrm{H}_{2} \mathrm{O}, \mathrm{LaCl}_{3} \cdot 7 \mathrm{H}_{2} \mathrm{O}$, $\mathrm{ErCl}_{3} \cdot 6 \mathrm{H}_{2} \mathrm{O}, \mathrm{TiOSO}_{4} \cdot \mathrm{xH}_{2} \mathrm{O}$ (Sigma-Aldrich Co. USA).

\subsection{Synthesis of MZP monoliths}

MZP macroporous monoliths were synthesized based on our previous reported method [16]. In a 
typical run, $1.29 \mathrm{~g}$ of zirconium chloride oxide octahydrate and an appropriate amount of metal sources (calculated based on the formula: $M_{1 / n}^{n+} \mathrm{Zr}_{2}\left(\mathrm{PO}_{4}\right)_{3}, M$ can be more than one kind of metal, $n$ represents the valence state of the metal in the metal source) was dissolved in the mixture of $1.4 \mathrm{~mL}$ of $1 \mathrm{M}$ hydrochloric acid aqueous solution and $1.6 \mathrm{~mL}$ of glycerol in a glass bottle. Predetermined amounts of PEO $\left(W_{\mathrm{PEO}}\right)$ and PAAm $\left(W_{\mathrm{PAAm}}\right)$ were then added to the solution (details are shown in Table S1). The mixture was kept stirred until a clear transparent solution was obtained, and the solution was then cooled at $0{ }^{\circ} \mathrm{C}$ in an ice-water bath. Then, $0.41 \mathrm{~mL}$ of concentrated phosphoric acid $\left(V_{\mathrm{H} 3 \mathrm{PO} 4}\right)$ that had been already cooled at $0{ }^{\circ} \mathrm{C}$ was added. The resultant solution was then kept stirred for $5 \mathrm{~min}$, followed by gelation at $0{ }^{\circ} \mathrm{C}$. The obtained wet gel was aged at room temperature for $5 \mathrm{~h}$ and dried at $60^{\circ} \mathrm{C}$ for three days, followed by calcination at different temperatures.

\subsection{Characterizations}

Morphology of the fractured surface of the samples and the chemical composition were investigated by scanning electron microscopy-energy dispersive X-ray spectroscopy (SEM-EDS, JSM-6060S,

JEOL, Japan). The crystal structure of the samples was confirmed by powder X-ray diffraction (XRD, RINT Ultima III, Rigaku Co., Japan) and high temperature XRD (SmartLab-SS, Rigaku Co. Japan, equipped with a high temperature control unit) using $\mathrm{Cu} \mathrm{K} \alpha(\lambda=0.154 \mathrm{~nm})$ as an incident beam. A platinum sample holder was used in high temperature XRD measurement and its position 
was calibrated every time before measurement to eliminate the effect of thermal expansion of the platinum holder. Thermal properties of the samples were investigated by thermogravimetry-differential thermal analysis (TG-DTA, Thermal Plus TG 8120, Rigaku Co., Japan) with a continuous air supply at $100 \mathrm{~mL} / \mathrm{min}$. Meso- and microporous structure of the samples were characterized by nitrogen adsorption-desorption (BELSORP-mini II, Bel Japan Inc., Japan). Skeletal density and mechanical property of calcined gels were investigated with a helium pycnometer (ULTRAPYC 1200e, Quantachrome Corp., USA) and a material tester (EZGraph, Shimadzu Corp., Japan), respectively. Coefficient of thermal expansion was measured by thermal mechanical analysis (TMA-60, Shimadzu Corp., Japan) at a heating rate of $10{ }^{\circ} \mathrm{C} / \mathrm{min}$ from ambient temperature to $1000{ }^{\circ} \mathrm{C}$.

\section{Results and Discussion}

\subsection{Synthesis of MZP monoliths}

The starting compositions for synthesizing MZP monoliths are listed in Table S1. In our previous work, synthesis of ZrP porous monoliths with different molar ratios of zirconium to phosphorous was reported. Starting from zirconium and phosphorous molar ratio as $2: 3$, by simply changing the kind of metal salt added to the starting composition, altogether more than 30 kinds of MZP porous monoliths have been successfully synthesized with different metal species including mono-, di- and 
trivalent metals as well as mixed metals with different molar ratios (Table S1). Figure 1 shows

SEM images and XRD patterns of the monovalent metal ( $\mathrm{Li}, \mathrm{Na}, \mathrm{K}, \mathrm{Rb}$ and $\mathrm{Cs}$ ) $\mathrm{ZrP}$ porous monoliths calcined at different temperatures. Monoliths with co-continuous macroporous structure interconnected by polycrystalline skeletons corresponding to $M \mathrm{Zr}_{2}\left(\mathrm{PO}_{4}\right)_{3}(M$ represents monovalent metal) were obtained. Similar results for di- and trivalent metals were shown in Figure $\mathbf{S 1}$ and $\mathbf{S 2}$. When metal salts dissolve in the solvent, hydrolysis occurs immediately, which releases a large amount of proton. Since the $\mathrm{pH}$ value of the solution is thus decreased, polymerization of metal species is largely inhibited. After all the starting reagents are mixed and a homogeneous solution is obtained, the polymerization between $\mathrm{Zr}$ species and phosphoric acid thus comes into domination. Simultaneously the polymers (PEO and PAAm) enhance phase separation with the progress of polymerization, and the transient structure of phase separation is frozen by the sol-gel transition, leading to the formation of such co-continuous macroporous structure. In the meantime, most of the other metals added remain dissolved in the solvent phase. After the evaporation of $\mathrm{H}_{2} \mathrm{O}$ and volatile components such as $\mathrm{HCl}$, the metal species were concentrated into glycerol and homogeneously distributed in the gel skeleton, which later diffused easily into the crystal lattice of $\mathrm{ZrP}$ at elevated temperature, giving rise to the MZP crystals. The difference in $\mathrm{pH}$ value after mixing all the starting reagents, which influences the kinetics of polymerization and thus the relative timing of phase separation and gelation of the solution, depends largely on the kind of added metal 
salt. Furthermore, the interaction between polymers (PEO and PAAm) and the added metal species, such as the coordination interaction between transition metals and amide groups in PAAm, may influence the interaction between the polymers and the $\mathrm{ZrP}$ network, which thus changes phase separation tendency. Consequently, the gel formation occurs at different intermediate state of phase separation, which leads to the differences in macropore sizes (for example, Figure $\mathbf{S 1} \mathbf{M g}, \mathbf{C a}, \mathbf{S r}$ and Figure S2 Al, Y, Fe).

Such synthetic method was proven to be applicable also in multiple metals systems. The morphologies (Figure S3 and Figure S4) and crystal structures (Figure S3 and Figure S5) of obtained multiple metals ZrP macroporous monoliths are shown. Regardless of their valence states, metals can be homogeneously mixed at any ratios in the $\mathrm{ZrP}$ network with the macroporous structure maintained by the synthetic method we have developed, suggesting the versatility for the synthesis of macroporous ZrP-based monoliths with metal species across the periodic table. An exception for lithium sodium $\mathrm{ZrP}$ was observed due to the decrease of crystallization temperature when two metals were mixed, thus calcination at $800{ }^{\circ} \mathrm{C}$ led to the crystal growth which collapsed the macroporous structure. The homogeneity of the co-mixed metals in the $\mathrm{ZrP}$ network was indicated by the EDX mapping of the sodium strontium $\mathrm{ZrP}$ macroporous monolith with a $\mathrm{Na} / \mathrm{Sr}$ ratio of

\subsection{4:0.38 (Figure S6).}

Since $\mathrm{Zr}$ is also tetravalent, it is reasonable to consider that $\mathrm{Ti}$ added here will occupy the same 
lattice position as $\mathrm{Zr}$. Therefore, instead of $2: 3$ as the starting molar ratio between $\mathrm{Zr}$ and $\mathrm{P}, 1: 2$ as the starting ratio between the total molar amount of $\mathrm{Zr}$ and $\mathrm{Ti}$ and the molar amount of $\mathrm{P}$ has been investigated. Figure S7A shows SEM images of pure zirconium pyrophosphate and titanium zirconium pyrophosphates with different Ti/Zr ratios. A drastic decrease of gelation time with increasing $\mathrm{Ti} / \mathrm{Zr}$ ratio led to the freezing of the transient structure of phase separation at an earlier stage, where the compositional difference between the gel-rich phase and the solvent-rich phase is not large enough. As a consequence, gels with small macropores and diffusive interfaces were formed, and the further increase of Ti/Zr ratio led to the deterioration of co-continuous macroporous structure. When the molar ratio between $\mathrm{Ti}$ and $\mathrm{Zr}$ reached $0.3 / 0.7$, gelation time was shortened to less than 1 min, making it very hard to control the gelation process. We therefore failed to obtain compositionally homogeneous macroporous monoliths when the molar ratio exceeded 0.3/0.7.

Figure S7B shows the X-ray diffraction peaks at different planes of titanium ZrP porous monoliths with different $\mathrm{Ti}$ to $\mathrm{Zr}$ molar ratios after calcination at $1000{ }^{\circ} \mathrm{C}$. As the amount of Ti increased, the diffraction peaks at each plane shifted to higher diffraction angle. Such results clearly indicate that Ti occupies the same lattice position as $\mathrm{Zr}$, and since the size of $\mathrm{Ti}$ is smaller than $\mathrm{Zr}$, the decrease of distance between planes could be speculated.

The tunability of macropore size of the obtained MZP monoliths is demonstrated in Figure S8 with SrZrP as an example. Simply by changing slightly the amount of PEO, the phase separation 
tendency can be changed; the more amount of PEO was added, the higher the phase separation tendency was, leading to the increase of macropore size.

\subsection{Effect of Heat treatment}

The crystallization process of MZP macroporous monoliths during heat treatment has been studied

with SrZP as an example. Figure 2 shows the SEM images of SrZP macroporous monoliths calcined at different temperatures. Macroporous structure were maintained even after calcination at

$1000{ }^{\circ} \mathrm{C}$. Results of TG-DTA are shown in Figure 3A. Endothermic peaks as well as the corresponding weight loss at temperatures lower than $100{ }^{\circ} \mathrm{C}$ and around $200{ }^{\circ} \mathrm{C}$ can be attributed to the evaporation of adsorbed water and glycerol as the solvent in the starting composition, respectively. The broad exothermic peak together with the weight loss starting from $250{ }^{\circ} \mathrm{C}$ to $500{ }^{\circ} \mathrm{C}$ is mainly due to the combustion of PEO and PAAm embedded in the gel skeleton as well as the decomposition of $\mathrm{SrCl}_{2}$ as the $\mathrm{Sr}$ source. No mesopores or micropores were found in the monoliths heat-treated at temperature below $300{ }^{\circ} \mathrm{C}$, while they started to appear when the heat treatment temperature was raised up to $300{ }^{\circ} \mathrm{C}$ with the BET surface area as $240 \mathrm{~m}^{2} / \mathrm{g}$ and mesopore size as $4 \mathrm{~nm}$. As the temperature was further increased, the BET surface area and the pore volume start to decrease and the mesopore size increases. Pores with different sizes in the range of tens of nanometers were confirmed when the sample was calcined at above $800{ }^{\circ} \mathrm{C}$, at which temperature, 
the pure $\mathrm{Sr}_{0.5} \mathrm{Zr}_{2}\left(\mathrm{PO}_{4}\right)_{3}$ phase was formed (Figure 3B, C, D, Table 1).

Since glycerol is nonvolatile and has a high boiling point $\left(290{ }^{\circ} \mathrm{C}\right)$, even after the evaporation of water during the drying process as well as the heat treatment at $120^{\circ} \mathrm{C}$, glycerol was still trapped in the gel network and acted as the solvent for $\mathrm{SrCl}_{2}$. Though it is difficult to incorporate $\mathrm{Sr}$ in the $\mathrm{ZrP}$ network due to the lack of strong interaction between them, the presence of glycerol in the gel network inhibits the precipitation and crystal growth of $\mathrm{SrCl}_{2}$, which leads to the homogeneous distribution of $\mathrm{Sr}$ in the monolith. However, the presence of glycerol in the monoliths heat-treated below $300{ }^{\circ} \mathrm{C}$ blocks the micropores and mesopores, as a result of which, no micropores or mesopores were found from $\mathrm{N}_{2}$ sorption isotherms of those samples. Complete removal of glycerol was achieved after heat treatment at more than $300{ }^{\circ} \mathrm{C}$, which was also confirmed by the appearance of both micropores and mesopores in the gel skeletons (Figure 3C). Due to the condensation of unreated hydroxy groups in the monolith at high temperature $\left(>600{ }^{\circ} \mathrm{C}\right)$, shrinkage of the monolith started to occur with a decrease of total pore volume. Calcination at even higher temperature (> $800{ }^{\circ} \mathrm{C}$ ) leads to the crystallization of the gel network. Mass transfer during this process as well as the tendency to decrease surface energy changed the nanoscopic morphology by eliminating micropores and small mesopores and yielding large mesopores. Larger nanometer-sized pores in the monoliths calcined at $800{ }^{\circ} \mathrm{C}(26 \mathrm{~nm})$ and $1000{ }^{\circ} \mathrm{C}(140 \mathrm{~nm})$ were formed as the interstitials between $\mathrm{Sr}_{0.5} \mathrm{Zr}_{2}\left(\mathrm{PO}_{4}\right)_{3}$ crystallites. 


\subsection{Thermal expansion and mechanical properties}

Though several reports discussed from experimental results that porosity has no obvious effect on the CTE value of porous ceramics $[25,26]$, traditional synthetic methods for the generation of three dimensional pores in ceramics, such as gelate freezing, pyrolytic reactive sintering, addition of porogen (inert gas or polymers) and self-assembly, find their difficulty to maintain nanometer scale pores in the ceramic body after calcination at high temperature [27], where the drastic crystal growth commonly leads to densified skeletons. Hence, the effect of porosity at nanometer scales on CTE of bulky ceramics has yet to be thoroughly studied. In this research, except for the micrometer scale macropores, small macropores $(66-140 \mathrm{~nm})$ that are close to mesopore $(2-50 \mathrm{~nm})$ in size were found present in the case of SrZrP monolith even after calcination at $1000{ }^{\circ} \mathrm{C}$. Such monolithic ceramic material with hierarchical porosity consisting of pure-phase crystallites is a matching candidate to study the effect of hierarchically porous structure on the bulk thermal expansion behavior.

Temperature-dependent bulk thermal expansion curves from TMA measurement for SrZrP monolith calcined at $1000{ }^{\circ} \mathrm{C}$ are shown in Figure 4A. The CTE value at the temperature range from $38{ }^{\circ} \mathrm{C}$ to $1000{ }^{\circ} \mathrm{C}$ was $1.4 \times 10^{-6} \mathrm{~K}^{-1}$, lower than that of $\operatorname{SrZrP}$ dense ceramics $\left(2.2 \times 10^{-6} \mathrm{~K}^{-1}\right)$ synthesized via solid-state reaction and sintered under pressure at the same temperature range [28] 
and can be classified as a material with ultralow thermal expansion $\left(\leq 2 \times 10^{-6} \mathrm{~K}^{-1}\right)[29]$. As a comparison, further densified SrZrP monolith (higher skeletal density and bulk density, Table 2) with only micrometer scale macropores were prepared by calcination at $1100{ }^{\circ} \mathrm{C}$ and $1200{ }^{\circ} \mathrm{C}$. The absence of nanometer scale macropores in those monoliths was confirmed from the very low $\mathrm{N}_{2}$ adsorption volume shown in $\mathrm{N}_{2}$ sorption isotherms Figure S9. The crystal size of the obtained monolith increased drastically from $\sim 100 \mathrm{~nm}\left(1000{ }^{\circ} \mathrm{C}\right)$ to $\sim 400 \mathrm{~nm}\left(1100{ }^{\circ} \mathrm{C}\right)$ and $\sim 1 \mu \mathrm{m}$ $\left(1200{ }^{\circ} \mathrm{C}\right)$ as the calcination temperature was increased (Figure 4B) and the crystal structure remained as $\mathrm{Sr}_{0.5} \mathrm{Zr}_{2}\left(\mathrm{PO}_{4}\right)_{3}$ even after calcination at $1200{ }^{\circ} \mathrm{C}$ (Figure S10). Though the total porosity remained similar, the CTE value were found increased when the SrZrP monolith was calcined at higher temperature due possibly to the presence of those small macropores in the skeletons calcined at lower temperature (Table 2). Such small macropores formed via mass transfer and crystal growth from amorphous gel network during the calcination process, can act as a free space to effectively buffer the geometrical change of the microcrystals and the possible formation of microcracks, which otherwise cause the significant decrease of mechanical strength at elevated temperature.

An inflectional increase in the CTE value was observed at the range between $550{ }^{\circ} \mathrm{C}$ and $650{ }^{\circ} \mathrm{C}$ for the SrZrP monoliths calcined at different temperatures. Such thermal expansion behavior has not been reported in metal(IV) phosphate-based low thermal expansion materials. The irrelevance 
of calcination temperature can exclude the crystal size and the pore structure as the possible reason for such behavior. Furthermore, no phase transition was observed from high temperature XRD patterns taken at this temerpature range for the $\mathrm{SrZrP}$ monolith calcined at $1000{ }^{\circ} \mathrm{C}$ (Figure S11). Lattice parameters calculated from high temperature XRD patterns (based on R-3 space group, Table S2) revealed that the expansion of unit cell volume was partially responsible for the overall thermal expansion behavior. An increase in the $a$ parameter was found much more significant at this temperature range as compared to that at $25{ }^{\circ} \mathrm{C}$, while the $c$ parameter remained almost unchanged, thus leading to the intense increase of unit cell volume.

Sufficient mechanical strength is always required for porous materials to be applied in a broader field. The mechanical properties of the SrZrP porous monoliths calcined at different temperatures were thus measured by uniaxial compression test and the results are shown in Figure $\mathbf{4 C}$ and Table 2. Increase of fracture strength (from $61 \mathrm{MPa}$ to $115 \mathrm{MPa}$ ) as well as Young's modulus (from 1.9 $\mathrm{GPa}$ to $3.9 \mathrm{GPa}$ ) was observed as the calcination temperature was increased from $1000{ }^{\circ} \mathrm{C}$ to $1100{ }^{\circ} \mathrm{C}$ due to the further densification of the skeletons at higher temperature. However, the further increase in the calcination temperature to $1200{ }^{\circ} \mathrm{C}$ led to the intensive crystal growth, resulting in reduced interface between crystallites, which thus reduced the fracture strength of the porous monolith. The bending property was measured by 3-point bending on the SrZrP monolith calcined at $1000{ }^{\circ} \mathrm{C}$ (Figure S12). The fracture strength and the flexural modulus were calculated 
to be $25 \mathrm{MPa}$ and $8.0 \mathrm{GPa}$ (strain range 0.1-0.2 \%), respectively. With sufficient mechanical strength and low CTE, porous MZP monoliths synthesized from sol-gel accompanied by phase separation can be applied in broad fields where high dimension stability is required at high temperatures.

\section{Conclusion}

In this research, a versatile methodology for the synthesis of MZP macroporous monoliths has been demonstrated with various metal species including mono, di tri and tetravalent metals as well as mixed metals. A homogeneous distribution of the metals in the gel has successfully been achieved, because the presence of a small amount of glycerol as a solvent with high boiling point prevents metal salt from recrystallization during the drying process. The post-heat treatment at high temperature $\left(>300{ }^{\circ} \mathrm{C}\right)$ removes glycerol from the colloidal $\mathrm{ZrP}$ network, which then yields mesopores, while further calcination at higher temperature $\left(\geq 800^{\circ} \mathrm{C}\right)$ gives rise to crystallization of the gel network to polycrystalline MZP. The thermal expansion and mechanical properties have been studied on $\mathrm{SrZrP}$ as an example. Ultralow thermal expansion (coefficient of thermal expansion (CTE) as $\left.1.4 \times 10^{-6} \mathrm{~K}^{-1}\right)$ over a wide temperature range $\left(38{ }^{\circ} \mathrm{C}\right.$ to $\left.1000{ }^{\circ} \mathrm{C}\right)$ together with sufficient mechanical properties has been demonstrated (flexural modulus as 8.0 GPa from 3-point bending and Young's modulus as $1.9 \mathrm{GPa}$ from uniaxial compression). As compared with dense 
ceramics of the same composition, the lower CTE value is observed and can be attributed to the presence of nanometer-sized small pores in the macropore skeletons, which absorbs the anisotropic thermal expansion of each crystallite at elevated temperatures.

\section{Acknowledgement}

The present work was financially supported by the Advanced Low Carbon Technology Research and

Development Program (ALCA) from the Japan Science and Technology Agency (JST) and Japan Society for the Promotion of Science (JSPS) KAKENHI Grant Number 15J00156. Miss Ronghuan Zhang from Oxford University is greatly acknowledged for the help in Rietveld refinement of high temperature XRD and the fruitful discussions.

\section{References}

[1] M. A. Alvin, T. E. Lippert, J. E. Lane, Am. Ceram. Soc. Bull. 70 (1991) 1491-1498.

[2] T. Ohji, M. Fukushima, Int. Mater. Rev. 57 (2012) 115-131.

[3] I. Ya. Guzman, Glass Ceram. 60 (2003) 9-10.

[4] M. E. Davis, Nature 417 (2002) 813-821.

[5] I. Sopyan, M. Mel, S. Ramesh, K. A. Khalid, Sci. Technol. Adv. Mater. 8 (2007) 116-123.

[6] A. Vu, Y. Qian, A. Stein, Adv. Energy Mater. 2 (2012) 1056-1085.

[7] M. Tiemann, Chem. A European J. 13 (2007) 8376-8388.

[8] K. Nakanishi, N. Tanaka, Acc. Chem. Res. 40 (2007) 863-873.

[9] D. Enke, F. Janowski, W. Schwieger, Microporous Mesoporous Mater. 60 (2003) 19-30.

[10] A. R. Studard, U. T. Gonzenbach, E. Tervoort, L. J. Gauckler, J. Am. Ceram. Soc. 89 (2006) 
$1771-1789$.

[11] A. EI Khadib, R. Chimenton, A. Sachse, F. Fajula, A. Galarneau, B. Coq, Angew. Chem. Int. Ed. 48 (2009) 4969.

[12] A. Sachse, V. Hulea, A. Finiels, B. Coq, F. Fajula, A. Galarneau, J. Catal. 287 (2012) 62-67.

[13] A. Sachse, A. Galarneau, F. Fajula, F. D. Renzo, P. Creux, B. Coq, Microporous Mesoporous Mater. 140 (2011) 58-68.

[14] N. Gargiulo, A. Verlotta, A. Peluso, P. Aprea, D. Caputo, Microporous Mesoporous Mater. 215 (2015) $1-7$.

[15] J. Konishi, K. Fujita, K. Nakanishi, K. Hirao, Chem. Mater. 18 (2006) 6069-6074.

[16] K. Kanamori, K. Nakanishi, T. Hanada, Adv. Mater. 18 (2006) 2407-2411.

[17] K. Kanamori, K. Nakanishi, Chem. Soc. Rev. 40 (2011) 754-770.

[18] Y. Tokudome, A. Miyasaka, K. Nakanishi, T. Hanada, J. Sol-Gel Sci. Technol. 57 (2011) 269-278.

[19] G. Hasegawa, Y. Ishihara, K. Kanamori, K. Miyazaki, Y. Yamada, K. Nakanishi, T. Abe, Chem. Mater. 23 (2011) 5208-5216.

[20] Y. Zhu, T. Shimizu, T. Kitashima, K. Morisato, N. Moitra, N. Brun, T. Kiyomura, K. Kanamori, K. Takeda, H. Kurata, M. Tafu, K. Nakanishi, New J. Chem. 39 (2015) 2444-2450.

[21] Y. Li, M. Liu, K. Liu, C. Wang, J. Power Sources 240 (2013) 50-53.

[22] R. Chourasia, O. P. Shrivastava, R. D. Ambashta, P. K. Wattal, Ann. Nucl. Energy 37 (2010) 103-112.

[23] D. K. Agrawal, C. Y. Huang, H. A. Mckinstry, Int. J. Thermophys. 12 (1991) 679-710.

[24] V. I. Pet"kov, E. A. Asabina, Glass Ceram. 61 (2004) 233-239.

[25] D.-M. Liu, J. J. Brown Jr., Mater. Chem. Phys. 33 (1993) 43-49.

[26] S. Ghabezloo, Constr. Build. Mater. 24 (2010) 1796-1798.

[27] Y. Suzuki, P. E. D. Morgan, MRS Bull. 34 (2009) 587-591.

[28] K. V. G. Kutty, R. Asuvathraman, R. Sridharan, J. Mater. Sci. 33 (1998) 4007-4013.

[29] R. Roy, D. K. Agrawal, H. A. Mckinstry, Annu. Rev. Mater. Sci. 19 (1989) 59-81. 
Table 1 Pore characteristics of SrZrP monoliths heat-treated at different temperatures.

\begin{tabular}{|c|c|c|c|}
\hline Temperature & $S_{\text {BET }} /^{2} \mathbf{m}^{-1}$ & $V_{\mathbf{p}} / \mathbf{c m}^{\mathbf{3}} \mathbf{g}^{-1}$ & $\mathbf{D}_{\mathbf{p}} / \mathbf{n m}$ \\
\hline $300^{\circ} \mathrm{C}$ & 240 & 0.17 & 4 \\
\hline $600^{\circ} \mathrm{C}$ & 180 & 0.16 & 4 \\
\hline $800^{\circ} \mathrm{C}$ & 33 & 0.10 & $11 / 26$ \\
\hline $1000{ }^{\circ} \mathrm{C}$ & 5 & 0.05 & $66 / 140$ \\
\hline
\end{tabular}


Table 2 Mechanical and thermal expansion properties, skeletal and bulk densities of SrZrP monoliths calcined at different temperatures.

\begin{tabular}{|c|c|c|c|c|c|c|}
\hline & $\begin{array}{l}\text { Strength } \\
\text { / } \mathrm{MPa}\end{array}$ & ${ }^{\mathrm{a}} E / \mathrm{GPa}$ & $\begin{array}{c}{ }^{\mathrm{b}} \mathrm{CTE} \\
/ 10^{-6} \mathrm{~K}^{-1}\end{array}$ & $\begin{array}{c}{ }^{\mathrm{c}} \rho_{\mathrm{s}} \\
/ \mathrm{g} \mathrm{cm}^{-3}\end{array}$ & $\begin{array}{c}{ }^{\mathrm{c}} \rho_{\mathrm{b}} \\
/ \mathrm{g} \mathrm{cm}^{-3}\end{array}$ & $\begin{array}{c}\text { Porosity } \\
\text { /\% }\end{array}$ \\
\hline $1000^{\circ} \mathrm{C}$ & 71 & 1.9 & 1.4 & 2.81 & 1.63 & 42 \\
\hline $1100^{\circ} \mathrm{C}$ & 115 & 3.9 & 1.6 & 3.15 & 1.80 & 43 \\
\hline $1200^{\circ} \mathrm{C}$ & 61 & 3.9 & 1.7 & 3.04 & 1.79 & 41 \\
\hline
\end{tabular}

${ }^{a} E$ represents Young's modulus calculated as $E=$ stress / strain at a strain range $0.1-0.2 \%$.

${ }^{\mathrm{b}}$ CTE represents coefficient of thermal expansion.

${ }^{\mathrm{c}} \rho_{\mathrm{s}}$ and $\rho_{\mathrm{b}}$ represents skeletal density and bulk density, respectively. 


\section{Figure captions}

Figure 1 SEM images and XRD patterns of monovalent metal ( $\mathrm{Li}, \mathrm{Na}, \mathrm{K}, \mathrm{Rb}, \mathrm{Cs}$ ) $\mathrm{ZrP}$ monoliths after calcination at $1000{ }^{\circ} \mathrm{C}$ for $2 \mathrm{~h}$ in the case of $\mathrm{Li}, \mathrm{Na}, \mathrm{K}, \mathrm{Rb}$ and $800{ }^{\circ} \mathrm{C}$ for $2 \mathrm{~h}$ in the case of $\mathrm{Cs}$ (calcination at $1000{ }^{\circ} \mathrm{C}$ leads to the overgrowth of $\mathrm{CsZr}_{2}\left(\mathrm{PO}_{4}\right)_{3}$ crystals and deteriorates the macroporous structure).

Figure 2 SEM images of SrZrP monoliths heat-treated at different temperatures $\left(120{ }^{\circ} \mathrm{C}, 200{ }^{\circ} \mathrm{C}\right.$, $\left.300{ }^{\circ} \mathrm{C}, 600{ }^{\circ} \mathrm{C}, 800^{\circ} \mathrm{C}, 1000^{\circ} \mathrm{C}\right)$.

Figure 3 TG-DTA curves of SrZrP monolith heat-treated at $120{ }^{\circ} \mathrm{C}(\mathrm{A}), \mathrm{XRD}$ patterns $(\mathrm{B}), \mathrm{N}_{2}$ adsorption desorption isotherms (C) and $\mathrm{BJH}$ pore size distribution obtained from the adsorption branch (D) of SrZrP monoliths calcined at different temperatures.

Figure 4 Temperature-dependent bulk thermal expansion curves (A), SEM images (B) and stress-strain curves from uniaxial compression tests (C) of $\mathrm{SrZrP}$ monoliths calcined at different temperatures for $5 \mathrm{~h}$. 


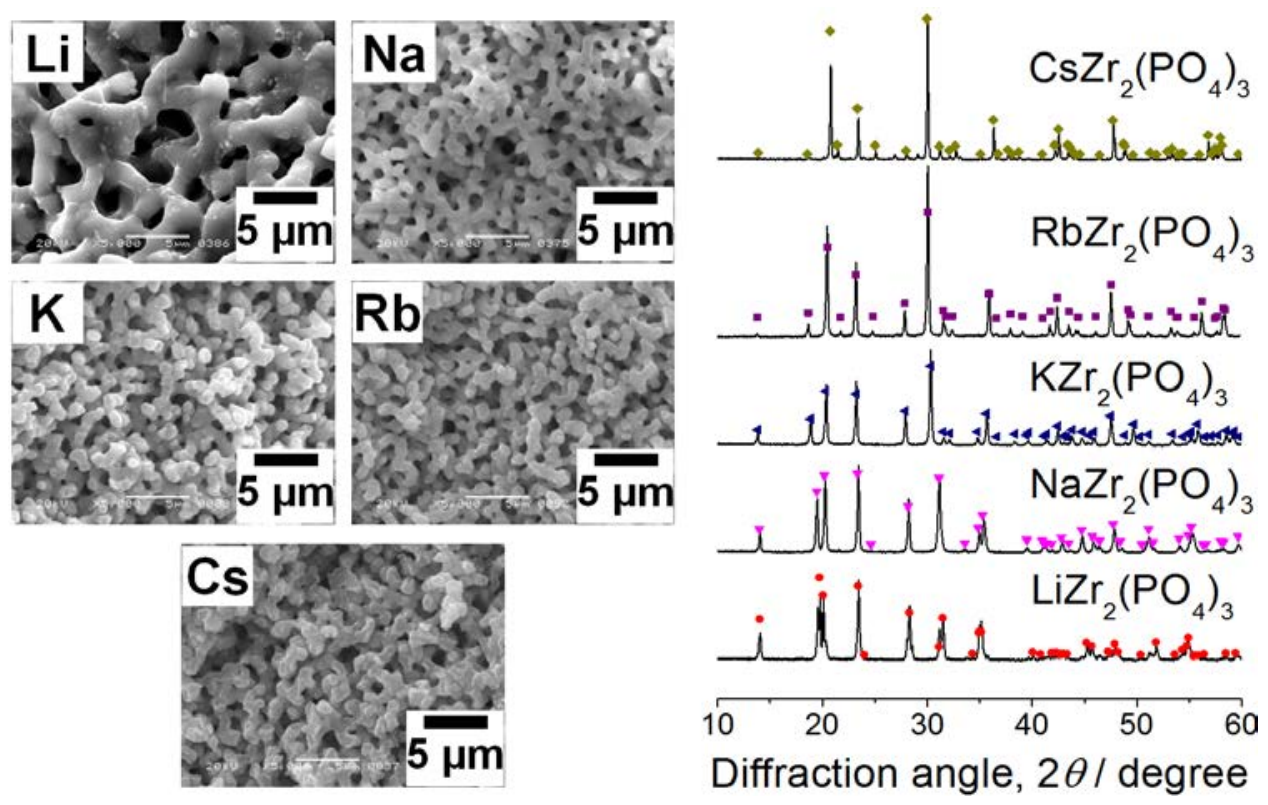

Figure 1 SEM images and XRD patterns of monovalent metal ( $\mathrm{Li}, \mathrm{Na}, \mathrm{K}, \mathrm{Rb}, \mathrm{Cs}$ ) $\mathrm{ZrP}$ monoliths after calcination at $1000{ }^{\circ} \mathrm{C}$ for $2 \mathrm{~h}$ in the case of $\mathrm{Li}, \mathrm{Na}, \mathrm{K}, \mathrm{Rb}$ and $800{ }^{\circ} \mathrm{C}$ for $2 \mathrm{~h}$ in the case of $\mathrm{Cs}$ (calcination at $1000{ }^{\circ} \mathrm{C}$ leads to the overgrowth of $\mathrm{CsZr}_{2}\left(\mathrm{PO}_{4}\right)_{3}$ crystals and deteriorates the macroporous structure). 


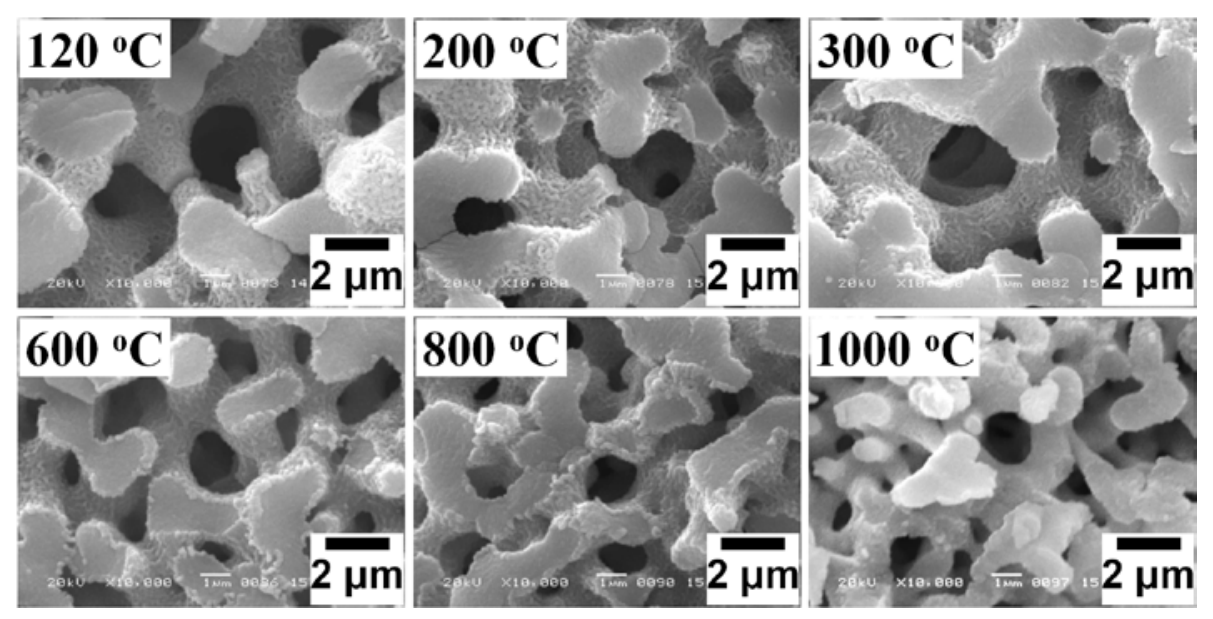

Figure 2 SEM images of SrZrP monoliths heat-treated at different temperatures $\left(120^{\circ} \mathrm{C}, 200{ }^{\circ} \mathrm{C}\right.$, $\left.300{ }^{\circ} \mathrm{C}, 600{ }^{\circ} \mathrm{C}, 800{ }^{\circ} \mathrm{C}, 1000^{\circ} \mathrm{C}\right)$. 
A
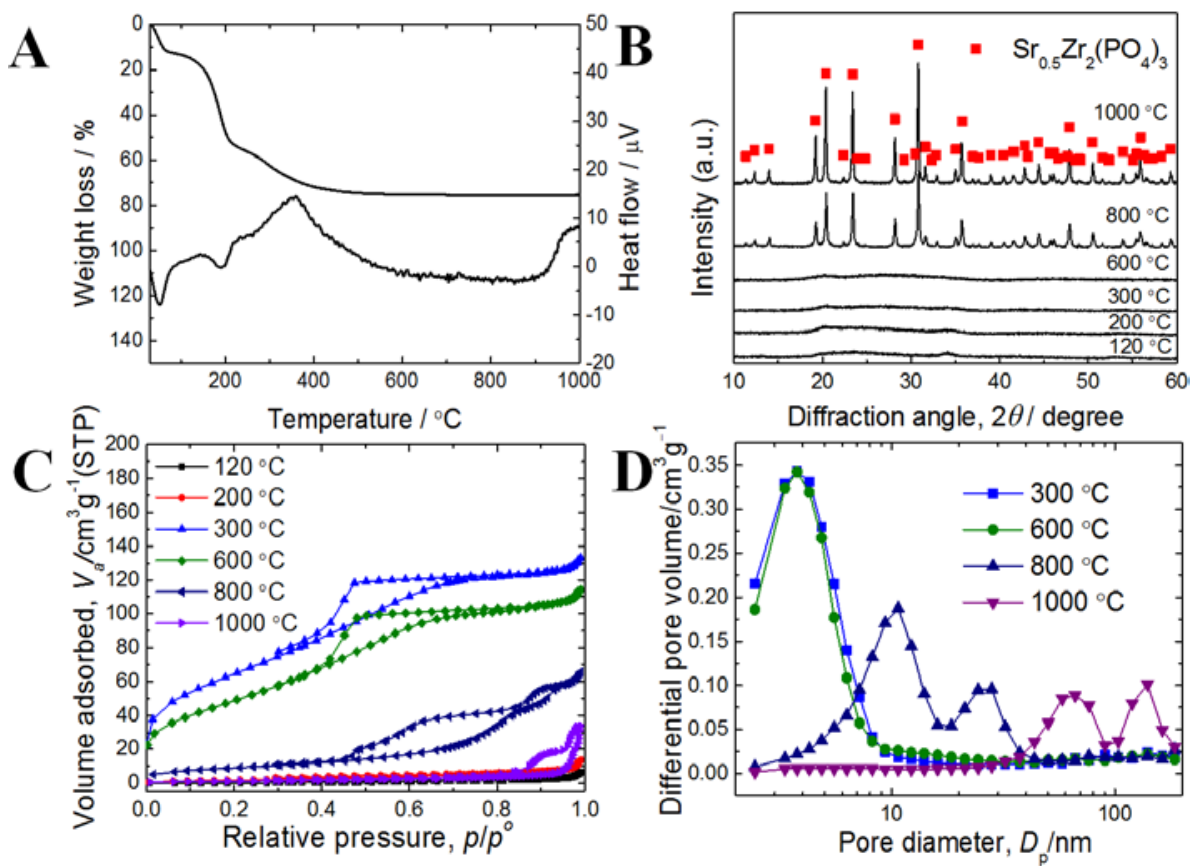

Figure 3 TG-DTA curves of $\mathrm{SrZrP}$ monolith heat-treated at $120{ }^{\circ} \mathrm{C}(\mathrm{A})$, XRD patterns (B), $\mathrm{N}_{2}$ adsorption desorption isotherms (C) and $\mathrm{BJH}$ pore size distribution obtained from the adsorption branch (D) of SrZrP monoliths calcined at different temperatures. 

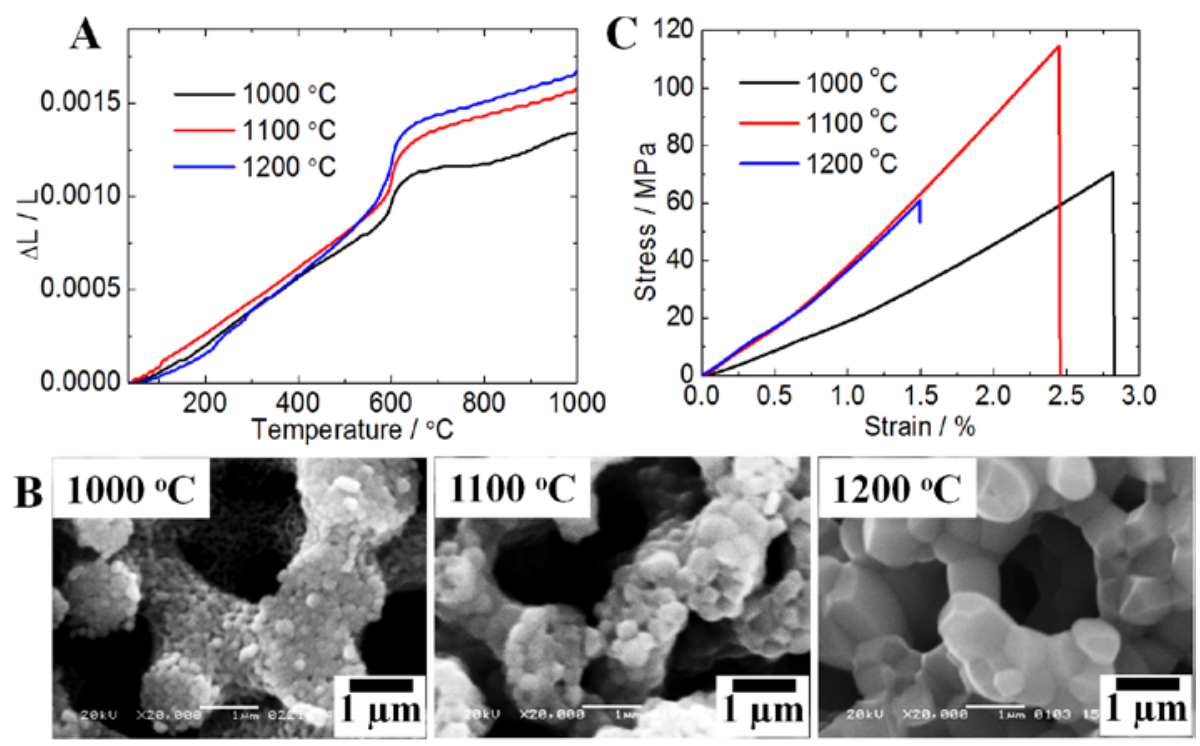

Figure 4 Temperature-dependent bulk thermal expansion curves (A), SEM images (B) and stress-strain curves from uniaxial compression tests (C) of SrZrP monoliths calcined at different temperatures for $5 \mathrm{~h}$. 
Graphical abstract

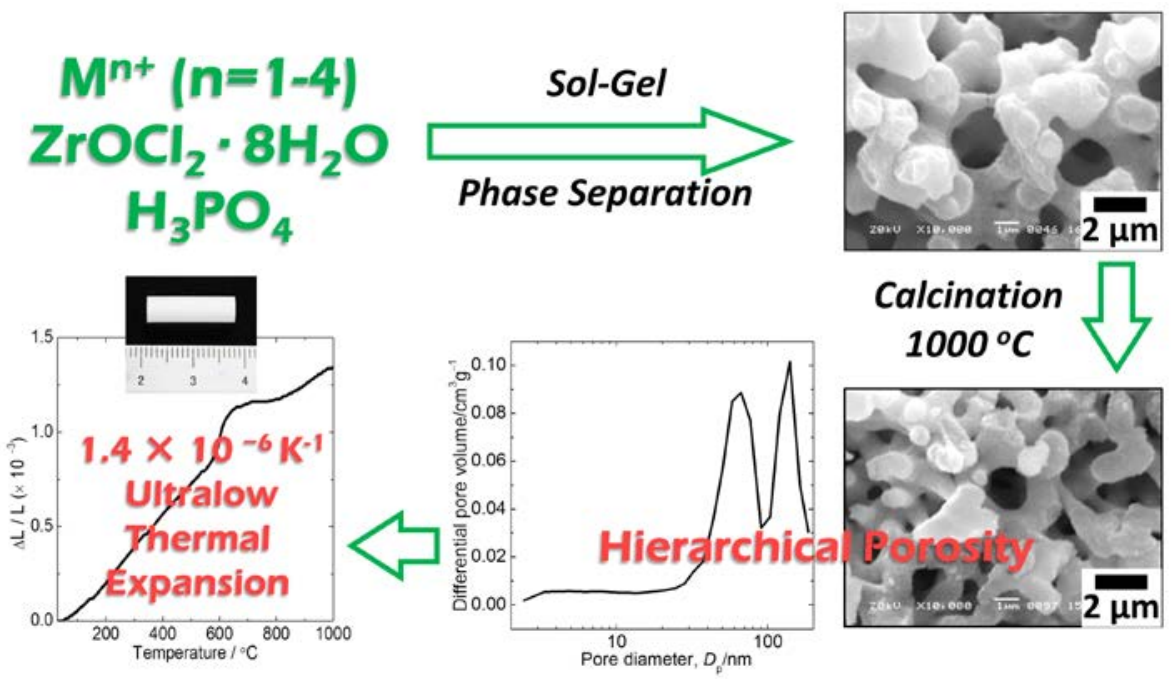

